\title{
Florence Nightingale - registered trademark for global nursing
}

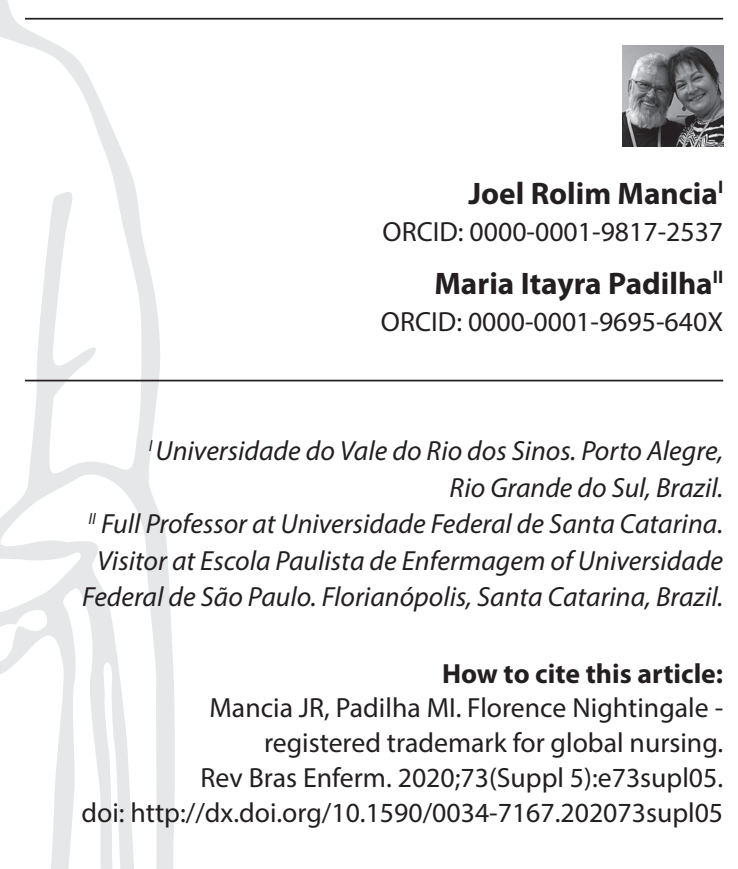

"Full Professor at Universidade Federal de Santa Catarina. Visitor at Escola Paulista de Enfermagem of Universidade Federal de São Paulo. Florianópolis, Santa Catarina, Brazil. eia JR, Padilha MI. Florence Nightingalev Bras Enferm. 2020;73(Suppl 5):e73supl05. doi: http://dx.doi.org/10.1590/0034-7167.202073supl05
When thinking about how to comment something about Florence Nightingale, without seeming repetitive, without news, or even unscientific, it is not an easy task. Performing a basic search for the name "Florence Nightingale" on the largest search platform worldwide, Google, in less than 47 seconds 16.600 .000 references appear referring to her name. We understand that these references include any and all forms of communication available online and gathered by the base, without necessarily representing the degree of importance of this personality as the tribute that we propose in this editorial.

Florence has long been sought as a resource for professional development, and has long been known for its contributions to nursing, education and health and public health reforms. Florence obtained international recognition for her participation in the Crimean War between 1854 and 1856.

In 2010, the centenary of her death was celebrated worldwide (05/12/182008/13/1910). On that occasion, the United Nations, on the initiative of "Sigma Theta Tau International", instituted the "International Year of the Nurse", as well as celebrating the $150^{\text {th }}$ anniversary of the creation of the first modern nursing school in the world, in the city of London, more precisely at Saint Thomas Hospital (1).

On that occasion, the movement for global health valuation was created and, consequently, the "Nightingale Declaration for a Healthy World", which was signed by millions of health professionals such as nurses, professors, professionals and caregivers worldwide, including Brazil. The movement's idea was to use this declaration as cornerstone of a global campaign, which would come to fruition in 2020, during the celebration of the $200^{\text {th }}$ anniversary of the birth of Florence Nightingale. The objective was, then, "Mobilization of Public Opinion on Health of Nations"(2).

The continuity of the campaign, which began in 2010, takes on a new vigor, starting in 2015, when an assessment of working conditions and nursing assessment begins at the global level, by All-Party Parliamentary Group on Global Health ${ }^{(3)}$. This assessment results in the report entitled Triple Impact, which pointed out similar problems and challenges faced by nurses. Nurses play an important role in health promotion and disease prevention, in addition to improving gender equality, taking into account wage and leadership differences between men and women and building stronger economies ${ }^{(4)}$.

Nursing Now was born out of Triple impact in 2018, with goals to be achieved by the end of 2020. All these goals had the ultimate goal of enabling the empowerment of nurses, the nursing staff and midwifery, considering 2020 as the "International Year of the Nurse and the Midwife". Nightingale Challenge (2019) is included in the same campaign, an initiative that aims to raise awareness among health employers, involving at least 1,000 organizations, to provide training and prepare 20,000 nurses, under the age of 35 , to exercise leadership and develop the next generation of young nurses as leaders, professionals, and health advocates, to demonstrate that nursing is a rewarding career ${ }^{(5)}$.

Coping with the coronavirus 2019 (COVID-19) pandemic, the campaign saw these goals take an unimaginable proportion in terms of the visibility of nursing 
and the importance of these professionals worldwide. The empowerment proposed by Nursing Now Campaign was present due to the tragedy that befell world society, and more than ever, it gave us the strength to believe in nursing care as the mainspring of health.

The representation of Florence Nightingale as an attentive, careful, present nurse, available for care, as well as a scientist professional, capable of creating new technologies for nursing care has emerged with all her strength today. During the pandemic, as in the Crimean War, there are cases where families are unable to accompany critically ill patients, they are dying. Nurses, then, have an important role as a channel of love between patients and family members, when separated at the end of life. Nurses today may not write letters like Nightingale; however, they can receive and share messages between patients and family members through the phone, tablets and other technologies, ensuring that the loved one can be comforted and not die so lonely ${ }^{(6)}$.

Florence Nightingale identified more than a century ago the need for attentive, empathetic and respectful nurse interaction, in addition to being a fierce advocate of patient well-being. The Lancet has endorsed its value for a long time, publishing a tribute to her person, immediately after her death:

Florence Nightingale's career and personality are so important because in her, the apostle of scientific nursing, it has been proven that such nursing does not - consist of the display of kind or zealous characteristics, (however faithful they may be, but they require recognition of the futility of any fight against the disease that is not based on knowledge of the physical causes behind the disease.... ${ }^{(7)}$

Nowadays, for instance, although Nightingale only fully supported the idea that many diseases are caused by specific microorganisms known as germs after the age of 60 , in the 1880 s she was very aware of the importance of hand hygiene. Although she wrote more than 50 books and manuals about health care in wars, her book, Notes on Nursing (1860), was more of a public health instruction book than a nursing manual, with important and current indications. In that book, she wrote that every nurse should be careful to wash their hands very often throughout the day, and, if washing the face, too, that would be even better ${ }^{(8)}$.

This was a relatively new piece of advice, first released by Hungarian physician Ignaz Semmelweis in the 1840s, who noted the dramatic difference this caused in maternity mortality rates. In addition, Nightingale considered the home to be a crucial place for disease prevention interventions. This was the place where most people contracted and suffered from infectious diseases. (The same is still true today: in the Wuhan coronavirus outbreak, $75-80 \%$ of transmissions were reported in households.)

Expert in statistics and images, she became a pioneer in graph use, to present data in a visibly clear way and so that everyone could understand its epidemiological meaning. Famous for creating the so-called "rose diagram", which she used to graphically represent mortality rates during the Crimean War. With this, she revolutionized the idea that social phenomena can be subjected to mathematical logic, and, using statistics, graphically illustrated the need for health reform. Florence Nightingale was the first woman to join the Royal Statistical Society in London ${ }^{(9)}$.

Florence Nightingale left her scientific, reflective and analytical spirit as a legacy to future generations, as she always defended her positions based on previous research. She can be considered the first research nurse in the world. Florence Nightingale believed that, through education, the human being could reveal his or her potential to change his or her situation, instead of conforming to it.

We understand that the current moment may mean a renaissance in nursing, considering that lay people, patients and society as a whole are looking at nursing with different eyes and greater appreciation. It is only fair that this occurs in the year in which the bicentenary of the birth of the woman who revolutionized patient care practices is celebrated.

\section{REFERENCES}

1. Harris MD. 2010: Commemorating the centennial year of the death of florence nightingale and the international year of the nurse. Home Healthc Nurse. 2010;28(8);510-12 doi: 10.1097/NHH.0b013e3181e8f9d4

2. Dossey B. Introducing the Nightingale Initiative for Global Health (NIGH) 2010-2020 [Internet]. 2010[cited 2020 Sep 25]. Available from: https://dosseydossey.com/barbara/nigh.html

3. All Party-Parliamentary Group on Global Health (APPG). Triple Impact: how developing nursing will improve health, promote gender equality and support economic growth [Internet]. 2016 [cited 2020 Sep 25]. Available from: http://www.appg-globalhealth.org.uk

4. Salvage J. Stilwell B. Breaking the silence: a new story of Nursing. Rev Enferm Ref. 2018;IV(17):3-12. doi: 10.1111/jocn.14306

5. Bayliss-Pratt L, Daley M, Bhattacharya-Craven A. Nursing Now 2020: the Nightingale Challenge. Int Nurs Rev. 2020;67(1):7-10 doi: 10.1111/inr.12579

6. Gallagher A. Learning from Florence Nightingale: a slow ethics approach to nursing during the pandemic. Nurs Inquiry. 2020 doi: 10.1111/nin.12369

7. The Lancet. Florence Nightingale. Lancet. 1910:571-2. doi: 10.1016/S0140-6736(00)52574-4

8. Nightingale F. Notes on Nursing: What is, and what it is not. London: Harrison, 1860.

9. Anderson RJ. Florence Nightingale: The Biostatistician. molecular interventions. 2011;11(2):63-5. doi: 10.1124/mi.11.2.1 